\title{
A Study on the Translation Aesthetics in Cathay based on Pound's Translation Theory of Recreation
}

\author{
Jianmin Kuang*, Zixun He \\ Central South University, Changsha 410083, Hunan Province, China \\ *Corresponding author: Jianmin Kuang, kjm305@csu.edu.cn
}

\begin{abstract}
This article expounds on Ezra Pound's translation anthology, Cathay by elaborating how he recreated classic Chinese poetry in modern English with his own translation aesthetics and theory. As both translation practice and recreation, Cathay exerts profound impact on global literatures and translations, conveying enlightenment to cultural exchanges between different civilizations. Based on Pound's translation theory, this article intends to unfold the aesthetics in Cathay including the beauty of exotic oriental culture, emotions that travels across time and space, and concise imagery through his recreation of connotations, themes, and text forms. Distinguishing from the precedents, Pound has made breakthroughs in the translation process, form, and criteria, valuing the translator's subjectivity. Nowadays, as overseas Chinese learners are increasingly keen in the Chinese culture, Pound's re-conceptualization of translation and cultural understanding can serve as rich references to cross-cultural exchanges and mutual learnings.
\end{abstract}

Keywords: Ezra Pound; Cathay; Translation aesthetics; Recreation in translation theory; Classic Chinese poetry

Publication date: July 2021; Online publication: July 30, 2021

\section{Introduction}

Earning a prominent reputation, Ezra Pound's masterpiece, Cathay marked a milestone in both, Imagism and translation for its recreation vigor. His dual identity as a poet and translator cultivated his aesthetics which have been represented in this translated anthology. Based on his translation theory, this article attempts to elaborate the enduring beauty of Cathay.

Controversial and acclaimed, Cathay is sometimes considered as an unattached work or as a supplementary material to The Cantos among foreign scholars. Although studies on Cathay involve diverse theories, the perspective of Pound's own translation theory should come into view. His aesthetics do not only exist in Imagist poetry but also in his translations. The combination of Pound's translation theory and aesthetics allows the generation of new ideas.

With a retrospective review of the East-West cultural exchange process, Ezra Pound's resounding translation anthology, Cathay cannot be neglected. Based on his recreation of this translation, the aim of this article comprises of two parts. The first is to rationalize Pound's recreation in translation by reinterpreting his translation strategies in accord with his poetics and the other is to elaborate how Cathay demonstrated his recreation through his own hermeneutics of translation.

\section{Pound's translation theory of recreation}

According to Pound's own translation criteria, he claimed that translation ought to be faithful to the "meaning" and "atmosphere" of the source language. Namely, he weighs the spiritual core and emotions 
over the literal form regardless of the disorganization in the structure or form, thus recreation accounted for a large part in his translations.

Believing that English translation should reproduce the authenticity of the source language, Pound tried his utmost to maintain the beauty of the original language for his readers. Moreover, Pound also alleged that language is endowed with a special energy whereby no matter how different languages are, they can connect people of various cultural backgrounds or epochs.

In order to move out of the conventional frame, Pound dedicated to the Imagism Movement (19081917). Based on his sensory perception, he asserted three main principles of Imagism which are the direct treatment of the "thing", no useless words, and the composition of rhythm in the sequence of musical phrase. Image in Pound's eyes has been defined as "an intellectual and emotional complex in an instant of time" which derived from directness and objectivity. Hence, the juxtaposition of images distinguishes Pound's poetry from others.

From the perspective of translation strategies, Pound has always emphasized the artistic atmosphere and maximum freedom to recreate instead of literal translation. In terms of purpose, Pound deemed that the selected translation subject should serve as fresh ideas to the citizens, society, as well as American literatures.

\section{Pound's recreation represented in Cathay}

As one of Pound's superb translation practice, Cathay matures and further expands his translation theories. Pound's dual identity as both poet and translator exerted profound influence on his translation theory of recreation with the interaction of his poetics and translation concept.

\subsection{Recreation of connotation: Beauty of oriental exoticism}

\subsubsection{Creation of proper nouns}

Pound's multilingual skills along with his mania for literature endowed him with a relatively equitable view on global literature. How little recognized this Chinese literature has been, this Far-East artistic classic finally caught Pound's attention. The contact with Chinese culture ignited his passion for translating oriental literature works and since then, he started his long-term assiduous work.

In order to strengthen the exoticism; the fresh vigor to intrigue the readers, Pound used an obscure and not-so-eloquent style in appropriate context by retaining direct elements of the source language or using archive words of the targeted language. Plenty alienated nouns in The River Song (江上吟) can be exemplified: “The boat is of shato-wood (沙棠舟),” “Sennin (仙人),” “Kutsu (屈平),” and “King So (楚 王).” Noticeably, Pound did not translate “仙人” into words of equal meaning like "immortal” or “gods” but interpreted it by transliteration, arousing the readers to question: Who is Sennin? Is he fictious or real? Why does he need a yellow stork? In other poems, transliterations like “Ko (京)," “Ten-Shin (天津)," “Kan Chu (汉中)," “East of Kan (汉东)," “Shin (晋)," “Choan (长安),” and “Hei Shu (并州)” are quite common as well.

Hence, in a bid to recommend the exotic culture to western readers, the person's name, toponym, and specific cultural terms have been interpreted in transliteration or for uncommon words, they remained partially faithful to the original text. These unfamiliar words with weird tonality have been created by Pound as a contrast to traditional poems of the Victorian style, thus refreshing the fixed usage of words. Although veiled, the silhouette of mysterious China can still be seized all over Cathay which intrigue readers to imagine and continue to appreciate it. 


\subsubsection{Portrait of ancient social customs}

In addition to creative interpretation of nouns, he also unfolded the scroll of ancient Chinese's social customs. For instance, elements of oriental civilization in social fields have been showcased in Exile's Letter (忆旧游寄谯郡元参军):

Example 1

红妆欲醉宜斜日

百尺清潭写翠娥

翠娥婵娟初月辉

And the vermilioned girls getting drunk about sunset

And the waters a hundred feet deep reflecting green eyebrows

Eyebrows painted green are a fine sight in young moonlight, gracefully painted -

美人更唱舞罗衣 And the girls sing back at each other, dancing in transparent brocade ${ }^{[1]}$

The translation above depicts the fashion of makeups and dressing in the Tang Dynasty. "Vermilioned girls (红妆)” signifies the prevailing way of girls applying heavy rouge to their cheeks with ceruse underneath to look pretty and attract the attention of men. This heavy makeup style and sharp color contrast between rouge and ceruse derived from the imperial concubine, Yang Yuhuan. Furthermore, "green eyebrows (翠娥)" signifies the use of a black pigment, “Dai (黛)" which has been once used by ancient maidens to paint their eyebrows. Rouge, dark green, and ceruse have been painted all over the dancing girls' faces. "Transparent brocade (罗衣)" are dresses weaved by silk which is extremely thin, hence looking as if they are transparent. The dressing and makeups reinforce the beauty and the curve of young women. The dancing girls in a luxurious feast seem to walk out from the poem, alive.

Apparently, translating involves well-rounded cultural knowledge in regard to customs, history, literature, philosophy, etc. Relentless learning about Chinese classics including poetry and Confucianism cultivates Pound's global view on literature and translation. With the inspiration of Chinese culture, Pound's translation theory and poetics interact forming his re-conceptualization of translation. Namely, it has been Pound's encounter with Chinese poetries which made him find the missing piece of Imagism and in turn, he then shared this amazing discovery with the world.

\subsection{Recreation of themes: Beauty of timeless emotions}

Pound alleged in his translation theory that conveying the emotion of poems is prior to recurring the literal structure or form. Proficient in capturing exquisite emotion, Pound has his unique criteria in choosing the subject of poems. Nostalgia and exile of frontier soldiers, heart-broken separation among intimates, loneliness, and the impermanence of time - such feelings travel through time and space which are shared by readers at different stages.

\subsubsection{Exile and trauma of war}

Among these topics, turbulence and misery of war have been the most favored as they echo with World War I (WWI). Born in the flames of the war, Cathay carries Pound's wishes for peace and goodwill as well as his intention to awaken people's awareness of how cruel the war is.

In order to convey direct impulse to the readers and surmount language barriers, Pound transforms archaic Chinese. Linguistically, the most forthright characteristics are colloquial and conversational so Pound substituted modern English for opaque archaism. As the Song of the Bowmen of Shu (诗经・采薇) represents: 
Example 2

曰归曰归, 岁亦阳止.

王事靡鹽，不遑启处.

We say: Will we be let to go back in October?

忧心孔疚, 我行不来.

There is no ease in royal affairs, we have no comfort.

Our sorrow is bitter but we would not return to our country ${ }^{[2]}$.

Here, Pound followed the view of frontier soldiers, pouring their torments and homesick feelings out for the readers as if they were intimates. Abandoning archaic words created a friendly and casual atmosphere without impairing the bitterness or core meaning of the original text. By this, the gap between the readers, the poet, and the protagonist is narrower. Explicitly, the author equated himself to the readers instead of leaving readers to look up to the artist. It has been a long time that people often feel detached from "art" but these familiar and colloquial expressions linked them.

This process withdraws the linguistic barriers of ancient Chinese, easing the Western readers in appreciating this work. Frankly speaking, fully understanding The Book of Songs is a knotty work even for Chinese people, not to mention the Western readers. However, this flexible recreation has become the bridge of the two civilizations. "Will we be let to go back in October?" is the expectation and question that every soldier has, yet the return date is repeatedly deferred. Although nobody would know when the war would end, they all aspire for a peaceful life. This expectation corresponds with the citizens during the WWI because all the soldiers and citizens suffered from endless wars no matter two thousand years ago or in 1914. The trauma and bitterness led by wars are feelings that all human beings empathize with.

\title{
3.2.2. Solitude and sorrow of women
}

Moreover, subjects like farewell among friends and women's lamentations are put on stage in western literatures due to Cathay's spectacular depiction. Sure, the feelings mentioned above are common experiences for readers around the world but they are rarely seen in American poetry. Hence, it is natural that Cathay has recommended new themes which are common in classic Chinese poetry. Feelings of farewell among friends are represented in the Four Poems of Departure while the lament of women can be exemplified by The Beautiful Toilet:

\author{
Example 3 \\ 娥娥红粉妆 White, white of face, hesitates, passing the door \\ 纤纤出素手 Slender, she puts forth a slender hand \\ 荡子行不归 And she has married a sot, \\ Who now goes drunkenly out \\ 空床难独守 And leaves her too much alone ${ }^{[3]}$
}

"White face" and "slender hand" depict the delicate figure of a woman. Even if the woman was beautiful enough to exude her charm and enjoy her youth, she finally married a sot, leaving her alone at night. Noticeably, ancient Chinese poems often express the regret of unfulfilled ambition in the perspective of lonely women but the feelings of these tragic women that Pound has interpreted are plainer. Nevertheless, the emphasis on women's miserable fate may be clues to female's awareness. Increasing attention has been given to the needs and sufferings of contemporary women with more female literary work mushrooming.

\subsection{Recreation of form: Beauty of concise imagery}

After long-term polishing, Pound's creative translation theory and poetics are incorporated entirely into Cathay which turned out to be another classic. Since the use of images has played a dominant role in classic 
Chinese poems over a thousand years, it is of no surprise that this feature edified Pound to create translation techniques with concise images. Still, Pound advocated the compact form and purification of classic Chinese poems which have been demonstrated in Cathay.

\subsubsection{Text form restructuring}

It has been acknowledged that Chinese language enjoys a high degree of syntactic freedom characterized by the absence of verbs and participles between nouns. The dynamic grammar has its advantage in foregrounding images, leaving different interpretations with uncommitted relations between those images. Poets have been eager to present images without personal involvements in their poems to arouse infinite poetic imaginations. Consequently, Pound attempted to reserve the syntactic feature whereby he constituted lines solely with nouns or noun phrases without connectives to indicate logical relations.

Example 4

青山横北郭 Blue mountains to the north of the walls

白水绕东城 White river winding about them

浮云游子意 Mind like a floating wide cloud

落日故人情 Sunset like the parting of old acquaintances

Syntactically speaking, in Pound's version, every line is made up of incomplete noun phrases alone without verbs. This syntax enabled the poet to assert prominence to vivid images of "blue mountains," "white river," "floating cloud," and "sunset." Pound's intention to abandon connectives between lines aimed to preserve the Chinese ambiguous syntactic relations. Meanwhile, reserving the Chinese syntactic structure freed him from the consideration of tense. With that, the sense of timelessness and universality in the original text have been successfully retained.

\subsubsection{Imagery overlapping}

As the forerunner of Imagism, Pound's aesthetics for image have sown the seed in his translation. Marking the milestone of the New American Poetry Movement (1912-1922), Cathay has been born to revolutionize translation and literatures, featuring impressive superposition and juxtaposition of images. The most typical example in Cathay is the Lament of the Frontier Guard (胡关绕风沙):

Example 5

荒城空大漠 Desolate castle, the sky, the wide desert

边邑无遗堵 There is no wall left to this village

白骨横千霜 Bones white with a thousand frosts

嵯峨蔽榛䒭 High heaps, covered with trees and grass $^{[1]}$

In the original text, “空” is often an adjective but it is alienated to a verb giving the meaning of making something empty or bleak. This line not only depicts an image of a post-war deserted frontier fortress with no soldier returning alive but also implies a dismal mood of the poet. Although Pound omitted the translation of "空," he perfectly delivered the readers to a desolate ancient battlefield by juxtaposition and superposition of images. "Castle," "sky," "desert," "wall," "village," "bones," "frosts," "heaps," "trees," and "grass" restore the cold-colored scene as if the readers are standing in a boundless desert overlooking only to find a desolate castle in the distance where the village used to be vibrant but then, it is now in ruins, encompassed by dust and relics under the sand and looking up, only the clear sky comes into view being 
dolorous and hopeless.

The line “惊沙乱海日: Surprised. Desert turmoil. Sea Sun.” in the South-Folk in Cold Country (古 风・ 代马不思越) also exemplified this characteristic. The most appealing ingenuity is that this line only consists of five Chinese characters in which Pound have also written five English words. Although they are not completely equal or corresponding, the overlapping images detain the reader's mind to sojourn in this line. "Surprised" lays the tone while "desert," "turmoil," "sea," and "sun" are unified to depict the bleak environment of a frontier desert. In this harsh circumstance, generals and soldiers have fought for decades without returning or any rewards until they die which infuriates the original poet to lament for these unknown heroes.

"Desert," "sea," and "sun" all showcase a boundless, remote, and alienated solitude in the reader's imagination. These images create concrete scenes as well as abstract symbols in the frontier soldiers' inner world. The charm of juxtaposition and superposition is elaborated by the empathetic images, manifesting Pound's intellectual "treatment" of imagery.

\section{Modern significance of Pound's translation}

Through the recreation of connotations, themes, and text forms, Pound has been endeavoring to unveil the beauty of oriental exoticism, timeless emotions, and concise imagery. Macroscopically, he unfolded the scroll of ancient China with abundant cultural and historical value while microscopically, he depicted the joy and misery in the ancient Chinese's social life.

Unlike the precedents, Pound has made breakthroughs in the translation process, form, and criteria. In regard to the process, he interpreted poems while recreating and emphasized the translator's subjectivity. As for the form, he has moved out of the traditional frame to free verse and absolute rhyme where he transformed archaic obscure words into modern English. In terms of criteria, faithfulness is no longer the requirement in Pound's eyes. In contrast, Pound regards the spiritual and emotional images as dominant factors by taking the reader's perception and empathy into account.

In the view of the traditional translation circle, Cathay is not an orthodox translation anthology because of the large-scale recreation that ran through Pound's translation process. His multiple identities as poet, translator, and critic generate specialty. Pound pursues poetic aesthetics as a poet, integrates poetics to the translation theory as a translator, and proposes new translation criteria for global literatures as a critic. These intertwined identities motivated Pound to re-conceptualize translation, poetry, and criticism.

The innovation of Pound's translation theory and poetics exerts far-reaching contributions in both literatures and translations. As Imagism explores new territories and brings about vigor to American literatures, the merits of Chinese poems are absorbed by western artists. With the wave of translation among different civilizations, cultural exchanges become more frequent and dynamic. Pound's translation practice on Chinese classics promoted Chinese literature in the Western literature circle, inspiring more and more western translators or sinologist to further dig into this mysterious eastern country.

\section{Conclusion}

Although recreation rejuvenates the original text, limitations and stumbles coexist. Firstly, inadequate Chinese historical study leads to logic and factual misinterpretations. Secondly, a deeper connotation of classic Chinese poems, allusion in particular has not been mentioned or expounded. Thirdly, the enchantment of the Chinese language along with its writing techniques have been lost such as splendid atmosphere, masterly rhyme, tone pattern (平大), and repetition. In spite of these limitations, western reader's reading experience has not been much affected. The choices that Pound have made are based on the purpose of conveying empathy. With this point, Cathay serves as a bridge between different 
civilizations.

To sum up, although Cathay is imperfect, it is undeniable that this translation anthology intrigues increasing western scholars to reexamine Chinese literatures. Its author, Pound, transforms the so-called subsidiary translation into vigorous recreation work which to some degree, can be called a literature. Moreover, his creativity and courage to revolutionize translation and literature still hearten scholars today to be innovative. At times, recreation leads to mistakes but mistakes can create new beauty.

\section{Disclosure statement}

The authors declare that there is no conflict of interest.

\section{Funding}

This work was supported by Humanities and Social Science Project of China's Ministry of Education (Grant number: 20YJAZH047).

\section{References}

[1] Hayot E, 1999, Critical Dreams: Orientalism, Modernism, and the Meaning of Pound's China. Twentieth Century Literature, 45(4): 511.

[2] Bellew, PB, 2017, At the Mercy of Editorial Selection: Amy Lowell, Ezra Pound, and the Imagist Anthologies. Journal of Modern Literature, 40(2): 22-40.

[3] Di F, 2014, A Study on Ezra Pound's Cathay from the Perspective of Deconstructionist Translation Theory.

[4] Venuti L, 2009, The Translator's Invisibility: A History of Translation (second edition), English Studies.

[5] Jiang H, 2001, Ezra Pound's Theory of Translation. Journal of Foreign Languages, (04): 78-81.

[6] Jiang H, 2001, New Directions of English Poetry - Research on the Poetic Theories and Cultural Criticism of Ezra Pound and Eliot. Hunan Education Publishing House.

[7] Wang G, 2005, On Ezra Pound's Conception of Translation and His Creative Rendering of Classical Chinese Poem. Chinese Translators Journal, :20-26.

[8] Wu Q, 2006, Ezra Pound and Chinese Culture, Shanghai Foreign Language Education Press.

[9] Barnes D, 2011, Geographies of Politics, Geographies of Literature: Ezra Pound and Italian Modernism. Comparative American Studies an International Journal, 9(2): 161-73.

[10] Jennings C, 2016, Pirating Pound: Drafts \& Fragments in 1960s Mimeograph Culture. Journal of Modern Literature.

[11] Kindellan MR, 2016, 'I Have Always Loathed Reading': On Ezra Pound's Late Cantos, Paideuma, 43.

[12] Baker W, 1997, The Cambridge Companion to Ezra Pound, Reference Reviews.

[13] Nord C, 2001, Translating as a Purposeful Activity, Functionalist Approaches Explained, Shanghai Foreign Language Education Press.

[14] Yu-Ting AN, 2016, A Study of Ezra Pound's Cathay from the Perspective of Rewriting Theory. 000(008): 134-6.

[15] Yip W, 2015, Ezra Pound's “Cathay”, Princeton University Press. 